\title{
Food neuropsychology and child brain development
}

\author{
Klaus W. Lange* and Katharina M. Lange
}

Department of Experimental Psychology, University of Regensburg, Germany

*Corresponding author: Klaus W. Lange, Institute of Psychology, University of Regensburg, 93040 Regensburg, Germany. Tel: +49 941 9433815; Fax: +49 941 9434496; E-mail: klaus.lange@ur.de

DOI: $10.31665 / J F B .2021 .13253$

Received: March 22, 2021; Revised received \& accepted: March 28, 2021

Citation: Lange, K.W., and Lange, K.M. (2021). Food neuropsychology and child brain development. J. Food Bioact. 13: 1-8.

\begin{abstract}
Accumulated adverse events, including insufficient nutrition, throughout pregnancy and infancy can disrupt brain development as well as early learning and cognition. Food neuropsychology research in childhood investigates the pathway from prenatal and postnatal nutrient supply to long-term brain function and mental health. Adequate food supply and nutrition from conception through infancy play an essential role in normal brain development and cognitive functioning and may also influence vulnerability to mental disease later in life. Neurodevelopmental processes, such as neuron proliferation, myelination and synaptogenesis, occur rapidly during pregnancy and infancy and are critically dependent on a sufficient supply of a variety of nutrients, including protein, omega-3 polyunsaturated fatty acids, iodine, iron and zinc. The investigation of the molecular basis of food effects on cognition and mood will help ascertain early-life nutritional requirements in order that brain functions and mental fitness may be enhanced. There is currently no convincing evidence of beneficial effects of nutrients or food bioactives in child mental disorders. Numerous issues in the examination of the effects of specific nutrients, including the identification of nutrients critical at different phases of brain development and the optimal dosage and duration of supplementation, require further research.
\end{abstract}

Keywords: Food neuropsychology; Brain development; Child cognition; Mental health; Prevention.

\section{Introduction}

Neural processes underlying early learning are influenced by genetic, epigenetic and environmental factors and have significant effects on subsequent development and health (Weaver, 2014). Adverse experiences early in the life course are linked to adult health (Black et al., 2017) and can have long-term disrupting effects on brain development and cognitive functioning (Shonkoff and Garner, 2012; Luby, 2015). Among various adversities, inadequate nutrition in prenatal and early postnatal stages carries the risk in affected individuals of failure to attain their developmental potential with respect to education, professional prospects, social relations and mental health (Lake and Chan, 2015; Walker et al., 2007). The important role of certain nutrients in the ontogenetic development of the central nervous system is well established (Georgieff and Rao, 2001; Kretchmer et al., 1996). Adequate nourishment and micronutrient supply is particularly important during pregnancy and infancy, when the brain develops most rapidly. Brain growth and function are dependent on a wide range of nutrients, but certain of these play key roles during early development. For example, folate is needed for neural tube development (Hibbard and Smithells, 1965 ) and iodine plays a vital role in neuronal plasticity (John et al., 2017). Other nutrients with significant effects on brain development include protein, essential fatty acids, choline, iron and zinc (Georgieff, 2007).

Most of the evidence regarding the biological mechanisms through which nutrient deficiencies may interfere with neurodevelopment at molecular and cellular levels stem from animal experiments. Neurodevelopmental processes that can be affected by these deficiencies in early life include proliferation of neurons, growth of axons and dendrites, myelination of neuronal membranes, formation of synapses and neuronal apoptosis (Prado and Dewey, 2014). While findings of animal studies have demonstrated the important role of food components in brain development, 
Table 1. Macronutrients and micronutrients in prenatal and infant brain development

\begin{tabular}{lll}
\hline Nutrient & Main role in developmental brain physiology & Main effects of deficiency \\
\hline Protein & $\begin{array}{l}\text { Cell proliferation and differentiation, } \\
\text { dendritic arborization, synaptogenesis }\end{array}$ & $\begin{array}{l}\text { Mild neurodevelopmental abnormalities (e.g. } \\
\text { impaired visual recognition memory) }\end{array}$ \\
$\begin{array}{l}\text { Omega-3 } \\
\text { fatty acids }\end{array}$ & Myelination, synaptogenesis & Cognitive deficits (e.g. attention, information \\
Folate & Neural tube development & processing); child mental disorders? \\
lodine & Cerebral cortex cytoarchitecture & Spina bifida, encephalocele \\
Iron & $\begin{array}{l}\text { Energy metabolism, myelination and } \\
\text { neurotransmitter production }\end{array}$ & Cognitive impairment \\
Zinc & $\begin{array}{l}\text { Neurogenesis, neuronal migration, } \\
\text { myelination and synaptogenesis }\end{array}$ & $\begin{array}{l}\text { Abnormal neurological reflexes and impaired auditory recognition } \\
\text { memory at birth; poorer neurodevelopment at school age }\end{array}$ \\
\end{tabular}

the development of permanent cognitive deficits or mental disorders as a consequence of inadequate nutrition in early ontogenesis depends on the interaction of these components with various other factors. Food neuropsychology is concerned with the way in which food and its components influence the nervous system, brain-behavior interactions, cognition, emotion and motor functions. The present short review summarizes the main scientific findings on food and child brain development and provides suggestions for future research.

\section{Food neuropsychology and child cognition}

The main macro- and micronutrients that have been identified as necessary in prenatal and infant brain and cognitive development include protein, omega-3 polyunsaturated fatty acids (PUFAs), iodine, iron and zinc (see Table 1).

\subsection{Protein}

The findings of animal models have demonstrated that protein restriction in early life results in reduced brain size, a less complex dendritic architecture, reduced synaptic numbers and a decrease in neurotransmitter and growth factor levels (Jones and Dyson, 1981; Wiggins et al., 1984; Winick, 1985). The special importance of protein, among other macronutrients, in achieving full neurodevelopment during the prenatal period and early childhood has also been shown in human studies (Pollitt et al., 1995). Fetal protein and/or energy malnutrition in humans causes intrauterine growth retardation (Low and Galbraith, 1974), which may be associated with impaired prenatal growth of the head (Strauss and Dietz, 1998) and mild neurodevelopmental abnormalities, including impairment of visual recognition memory (Gotlieb et al., 1988; Spinillo et al., 1993).

\subsection{Omega-3 fatty acids}

Omega-3 PUFAs are constituents of cell membranes and are essential for normal brain function. Animal studies have demonstrated that omega-3 PUFAs, particularly docosahexaenoic acid (DHA), are involved in neurogenesis, neuronal migration, synaptogenesis as well as fatty acid composition and fluidity of neuronal membranes (Innis, 2008). Since omega-3 PUFAs are essential for brain growth and development during pregnancy and infancy (Kris-
Etherton et al., 2009), sufficient dietary supply is indispensable for normal cognitive and motor development in childhood (Clandinin et al., 1980a, 1980b; Colombo et al., 2004; Helland et al., 2003; Luxwolda et al., 2014). Dietary deficiency of omega- 3 fatty acids appears to impair learning and memory in rodents (Bourre et al., 1989; Moriguchi et al., 2000). In non-human primates, early PUFA levels have been found to have modulatory effects on prefrontal cortex functions, such as attention, impulsivity and inhibition (Neuringer et al., 1986). The findings of studies in preterm humans have suggested beneficial effects of DHA for retinal and cognitive development (O'Connor et al., 2001; SanGiovanni et al., 2000). The results of other human studies of potential benefits of omega-3 PUFA supplementation during gestation, lactation and infancy on attention and cognition have been mixed (Delgado-Noguera et al., 2010; Simmer, 2001). However, long-term follow-up appears to be essential in food supplementation studies, since benefits of PUFAs administered in the first year of life may become apparent only at age 3-6 years (Colombo et al., 2013). The accumulation of omega-3 PUFAs in neuronal membranes may contribute to increased information processing, improved attention and enhanced cognition in children (Vollet et al., 2017). Maternal supplementation with omega-3 PUFAs during pregnancy and lactation has been reported to augment children's intelligence quotient at 4 years of age (Helland et al., 2003). Dietary enrichment with PUFAs has also been shown to positively impact children's general cognitive competence as well as learning, memory and language (Øyen et al., 2018). Furthermore, omega-3 PUFA supplementation was associated with a decrease in deficits in reading and spelling in children with developmental coordination disorder (Richardson and Montgomery, 2005). In children deemed "normal" in their general ability but "not fulfilling their potential at school", improved school performance was seen in those receiving omega-3 PUFAs (Portwood, 2006). This finding needs to be confirmed by highquality randomized trials.

\subsection{Iodine}

The role of iodine in brain development is related to thyroid hormone synthesis. An insufficient intake of iodine in prenatal stages and infancy can permanently and irreversibly disturb the cytoarchitecture of the cerebral cortex (John et al., 2017; Williams, 2008). Animal studies have shown that prenatal iodine deficiency is linked to deficient neurogenesis and neuronal migration, while postnatal deficiency affects dendritogenesis, synaptogenesis and myelination (Dong et al., 2005; Navarro et al., 2015). Behavioral 
abnormalities observed in animals include impairments in learning and memory and sensory gating as well as increased anxiety-like behaviors (Navarro et al., 2015). Severe prenatal iodine deficiency in humans can cause cretinism with irreversible changes in brain development, including deficits in hearing, speech and motor functioning (Skeaff, 2011), as well as a reduced intelligence quotient (Bath et al., 2013).

\subsection{Iron}

A key role of iron in human brain development, including energy metabolism, myelination and neurotransmitter synthesis, has been demonstrated in numerous studies (Beard and Connor, 2003). Rodent experiments have found that iron is necessary for the structural, neurochemical and functional development of the fetal brain (Carlson et al., 2009; Greminger et al., 2014; Lozoff et al., 2006). Behavioral consequences of iron deficiency in rodents include deficits in trace recognition memory (McEchron et al., 2005), procedural memory (Beard and Connor, 2003) and spatial navigation (Felt and Lozoff, 1996). Human infant iron deficiency has been shown to be associated with abnormal neurological reflexes (Armony-Sivan et al., 2004) and impaired auditory recognition memory at birth (Siddappa et al., 2004). Infants with low cord serum levels show poorer neurodevelopment at five years of age (Tamura et al., 2002).

\subsection{Zinc}

Zinc is a cofactor in enzymes involved in the biochemistry of proteins and nucleic acids (Sandstead, 1985), and fetal zinc deficiency leads to a reduced brain content in DNA, RNA and protein (Duncan and Hurley, 1978). Animal studies have shown that zinc is needed for neurogenesis, neuronal migration, myelination and synaptogenesis (Adamo and Oteiza, 2010). Behavioral effects of zinc deficiency in early life in humans include disturbed attention, learning, memory and mood (Golub et al., 1995), and a positive impact of zinc supplementation in early infancy has been reported (Black et al., 2004; Colombo et al., 2014). Fetuses of zinc-deficient mothers have been observed to show reduced movement and heart rate variability, which suggests impaired stability of the autonomic nervous system (Merialdi et al., 2004).

\section{Food neuropsychology and child mental disorders}

Food and diet are increasingly recognized as critical not only for early brain development and cognition but also as potentially modifiable factors influencing mental health outcomes in children (Lange, 2018a). While the factors contributing to mental health are manifold and complex, maternal nutrition and early-life diet appear to be associated with behavioral and emotional dysregulation and neuropsychiatric conditions in childhood (O'Neil et al., 2014). Severe macronutrient deficiencies during early development have been linked to the pathogenesis of depressive and psychotic disorders (Brown et al., 1995; Susser and Lin, 1992). Furthermore, the findings of several prospective cohort studies have shown that prenatal and early postnatal nutrition are associated with internalizing and externalizing problems in children aged 5-7 years (Jacka et al., 2013; Pina-Camacho et al., 2015; Steenweg-de Graaff et al., 2014). In addition, various vitamins, trace elements and omega-3 fatty acids have been suggested to play a role in child mental dis- orders (Lange, 2017, 2018b, 2020a; Lange et al., 2017). For example, dietary omega-3 PUFA deficiency has been associated with an increase in the risk of several mental disorders in children, such as attention deficit/hyperactivity disorder (ADHD), autism spectrum disorders (ASD) and mood and psychotic disorders (Lange, 2020b, 2020c). However, epidemiological studies reporting correlations between nutrient levels and the presence or severity of psychiatric symptoms do not allow any conclusions on causality. Since numerous intervention studies examining the potential therapeutic effects of nutrients in mental disorders have employed study designs lacking an appropriate control group, the results reported may be due to placebo effects. Long-term randomized controlled trials are largely absent. There is therefore no convincing evidence of beneficial effects of nutrients or food bioactives in child mental disorders.

\subsection{Elimination diets}

In addition to nutrient deficiencies, antigenic properties of food components have been hypothesized to be involved in child mental disorders. For example, a causal involvement of the proteins gluten and casein in the pathogenesis of ASD has been suggested (Lange et al., 2015), and gluten-free/casein-free diets are believed to be capable of ameliorating the behavioral symptoms in children. However, the scientific rigor of many available intervention studies is low, and rigorous scientific evaluations found no evidence of effectiveness of the gluten-free/casein-free diet in the treatment of ASD (Reissmann et al., 2020).

On the basis of the hypothesis that artificial food additives may be involved in the occurrence of ADHD symptoms, elimination studies have examined the effects of the exclusion of artificial food additives or of a few-foods diet in children with ADHD. A meta-analytical review reported a small effect size of food additive elimination (Nigg et al., 2012). Furthermore, the small effect sizes found for artificial food color elimination in placebo-controlled trials provide no convincing evidence of its therapeutic efficacy, while the medium-to-large effects of the few-foods diet suggest that this approach may offer a treatment option (Pelsser et al., 2017). In addition, the use of oligoantigenic diets and subsequent reintroduction of nutrients can reveal food-related intolerances or allergies. This approach is currently under investigation (Dölp et al., 2020) .

\section{Future directions}

While various nutritional deficiencies, such as chronic undernutrition and insufficient iodine and iron supply, have clearly been shown to impair brain development, evidence of the effects of micronutrient powder supplementation and salt iodization is scarce, and further investigations are therefore called for.

\subsection{Time, extent and duration of nutrient deficiency}

The effects of nutrient deficiencies on early brain development depend on time, extent and duration (Kretchmer et al., 1996). The time of nutrient deficiencies appears to be of particular importance (Cusick and Georgieff, 2012). Critical or sensitive ontogenetic periods are times of particular receptiveness or vulnerability to certain environmental and other factors, such as maternal health, social stimulation and deprivation, stress, toxins or nutrients. These factors are of critical importance for normal brain development, 
with a deficiency resulting in irreversible long-term consequences for brain structure or function (Bornstein, 1989; Colombo, 1982). For example, the hippocampus develops earlier than the prefrontal cortex and therefore the time period of insufficient supply of a nutrient affecting the arborization of neuronal dendrites will determine which of these brain regions sustains more profound damage. A neuronal circuit requiring a balanced input from both hippocampus and prefrontal cortex, such as the ventral tegmental area, may show significant behavior-related pathology, e.g. related to psychotic disorders, as a consequence of unbalanced input (Tseng et al., 2009; White and McDonald, 2002).

The significance of the stage in infant development during which iron supply is deficient has been investigated. While iron/ folic acid supplementation during pregnancy produced better results in the offspring in tests of intellectual, executive and motor function in comparison with placebo controls (Christian et al., 2010), supplementation in children aged 12-35 months showed no effect (Murray-Kolb et al., 2012). Furthermore, excessive administration of iron may lead to worse neurodevelopmental outcomes. In a 10-year follow-up study of iron supplementation in 6-monthold infants, those with high hemoglobin receiving iron performed significantly worse 10 years later in a neurodevelopmental task battery, while infants with low hemoglobin receiving iron showed a significantly better performance (Lozoff et al., 2012). These findings demonstrate that a nutrient may be beneficial at one dose or time and toxic at another.

Research on specific nutrients has yet to ascertain both the effects of individual compounds during critical phases of brain development and the optimal dosage and duration of supplementation.

\subsection{Combination of nutrients and dietary patterns}

The majority of available studies have investigated the brain-related and behavioral effects of individual nutritional components, food bioactives or supplements. However, individual nutrients can interact with one another and may have synergistic (or antagonistic) effects on specific functions. Food research has therefore focused increasingly on dietary pattern analysis ( $\mathrm{Hu}, 2002)$. Multiingredient supplementation may be needed to achieve beneficial effects in mental disorders in particular, since they are clinically complex and etiologically heterogeneous.

In a study assessing cognitive functioning, children aged 6-12 years receiving a beverage containing omega- 3 fatty acids and various micronutrients (iron, zinc, folate and vitamins A, B6, B12 and $\mathrm{C}$ ) showed higher scores in tests assessing learning, memory and verbal intelligence after 6 and 12 months (Osendarp et al., 2007). In order to separate out the role of individual nutrients in the improved test results, it would be necessary to perform several concurrent studies examining single components. However, certain dietary components may act in an additive or synergistic fashion, and the assessment of dose-response relationships for all potentially relevant nutrients poses numerous logistic challenges.

A possible role of dietary patterns has been investigated in children and adolescents diagnosed with ADHD. A large populationbased cohort study reported that ADHD diagnosis was associated with a higher score for a 'Western' dietary pattern, but not with a 'healthy' dietary pattern (Howard et al., 2011). An inverse association has been found between ADHD and a nutrient pattern rich in zinc, protein and other minerals (Zhou et al., 2016). Furthermore, low adherence to a Mediterranean diet was associated with an increase in the prevalence of ADHD diagnosis (Ríos-Hernández et al., 2017). Hyperactivity was positively correlated with the con- sumption of processed meat and salty snacks and negatively associated with the consumption of vegetables, coarse cereals, aquatic foods, beef and mutton (Liu et al., 2014). However, the findings are based on observational study designs which allow no conclusions regarding causal relationships between ADHD and diet.

There is a paucity of randomized controlled trials examining the effectiveness of dietary change in mental health. Emerging evidence in adults suggests that adherence to a Mediterranean-style diet has beneficial effects on mental health in individuals with depression (Parletta et al., 2019; Sánchez-Villegas et al., 2019), and significant improvements in mood and decreased anxiety levels have been observed in adults with major depression (Jacka et al., 2017; Jacka et al., 2018). However, randomized controlled trials assessing the Mediterranean or other diets in early life are not available.

\subsection{Role of the microbiome}

Research on the interaction between intestinal microbiota and the brain has come into focus in research, since the microbiome appears to provide a link between the gut and brain function (Dinan et al., 2015; Fernandez-Real et al., 2015; Sarkar et al., 2018). In particular, gut microbiota have been suggested to play a role in responses to stress (Dinan and Cryan, 2012) and the risk of childhood mental disorders, such as ADHD and ASD (Lange et al., 2020). However, the recent hype in microbiome research, including claims that interventions targeting intestinal microbiota might offer potential avenues for the enhancement of cognition or the treatment of mental disorders, needs to be put into perspective. The available studies have shown correlational but no causal relationships and have been unable to detect distinct microbiota patterns related to different mental disorders (Lange et al., 2020). Largescale, prospective trials need to investigate the clinical relevance of findings in animals and the validity of the intestinal microbiome as a target in the prevention or treatment of mental disorders.

\subsection{Adverse effects of food supplements}

In regard to the administration of nutritional supplements, possible adverse effects of seemingly natural and healthy nutrients should be taken into consideration. For example, long-term omega-3 PUFA administration may be associated with an elevated cancer risk, possibly due to PUFAs, their oxidation products or added $\alpha$-tocopherol (Lange et al., 2019). Therefore, caution is needed when food supplements are administered over extended periods of time and during vulnerable phases of life, especially in infancy and childhood. Adverse effects may become apparent many years after supplementation and their cause may therefore fail to be recognized.

\subsection{Further aspects}

In addition to the above mentioned aspects of time, extent and duration of nutrient deficiency, a child's psychosocial environment should be considered in the design of future research. In a recent cross-sectional cohort study of early school-aged children, caregiving behaviors, such as quality of parent-child relationship and parental stress, have been shown to modify the association of children's gut microbiome with socioeconomic risk and behavioral dysregulation (Flannery et al., 2020). Nutritional supplementation may produce positive effects on development only if combined 
Table 2. Research issues of food neuropsychology and child brain development

Further identification of foods critically important for normal brain development

Effects of time, extent and duration of nutrient deficiencies on early brain development

Long-term effects of early nutritional deficiency on behavior, cognition and mental health across the entire lifespan

Role of single nutrients versus dietary patterns and whole diets

Obesity and mental health problems in later life

Correlational or causal association of gut microbiota with cognition or mental disorders

Identification of distinct microbiota patterns related to different child mental disorders

Interaction of food-related factors with psychosocial and environmental factors

Food neuropsychology and public health policies

with a certain amount of stimulation from the environment. For example, developmental benefits following zinc supplementation were seen in Jamaican infants aged 9-30 months only if they participated in a psychosocial stimulation intervention (Gardner et al., 2005). Thus, improvement of nutrition alone may be insufficient to improve brain development.

Child brain development may be affected not only by nutritional deficiency but also by an overabundance of food resulting in overweight and obesity. Maternal obesity during pregnancy appears to be associated with an elevated risk for a wide range of physical health, cognitive and mental health problems in offspring across the entire lifespan (Contu and Hawkes, 2017). High prenatal maternal body mass index has been found to be associated with differences in cognitive performance of offspring at age 5 years (Basatemur et al., 2013) and in affective and social functioning at ages 5-6 years (Jo et al., 2015; Robinson et al., 2013; Rodriguez, 2010). Elevated prenatal body mass index has also been associated with ADHD and ASD in early and middle childhood (Getz et al., 2016; Sanchez et al., 2018). Furthermore, changes in fetal brain connectivity, as assessed using functional MRI, have recently been shown to be associated with elevated maternal body mass index during pregnancy, with a tendency for elevated within-hemisphere connectivity and a decrease in cross-hemisphere connectivity (Norr et al., 2020). This may have implications for the long-term cognitive development and mental health of the offspring. Little is known about the associations between brain development and overweight or obesity in children. In a group of over 3,190 children with a mean age of 10.0 years, those with a higher body mass index were found to exhibit lower thickness of 18 regions of the cerebral cortex, with the greatest correlation observed in the prefrontal cortex (Laurent et al., 2020). In addition, body mass index was inversely correlated with scores in tests of executive functions, such as working memory (Laurent et al., 2020). These findings suggest that child obesity is associated with the development of the prefrontal cortex. In addition, the complex relationships between obesity and mental health are thought to potentiate the severity and interdependence of each other (Small and Aplasca, 2016).

Research on the role of nutrients in mental disorders is hampered by their problematic classification and heterogeneous nature. An objective and reliable classification based on biological hypotheses is needed (Haber and Rauch, 2010; Insel and Cuthbert, 2009). Most mental disorders are ill-defined constructs and lack biological or neuropsychological markers underpinning their validity. At present, the preventive or therapeutic efficacy of nutrients in child mental disorders can be evaluated using only subjective and questionable symptom ratings rather than objective pathophysiological measures or neuropsychological biomarkers.
Major research issues of food neuropsychology and child brain development are presented in Table 2.

\section{Conclusion}

Normal brain development is critically dependent on sufficient food supply and nutrition. A balanced diet from conception through infancy is essential in providing an adequate nutrient supply to allow an undisturbed development of brain and cognitive function. Furthermore, food and diet seem to be modifiable intervention targets for the prevention of common mental disorders.

Current epidemiological findings on food and mental health cannot establish causality or provide information on the underlying mechanisms. Further scientific evidence demonstrating an unequivocal link between nutrition and mental health is therefore needed. Foods and dietary components critically important for brain health and possibly mental disease as well as the timing, dosage and duration of nutritional interventions providing preventive and therapeutic efficacy require further investigation.

The effects of dietary factors normally become apparent in the long term and their importance for public health is therefore frequently underestimated. Nutritional deficiencies during pregnancy and infancy may have effects on behavior, cognition and mental health throughout childhood, adolescence and adulthood. Thus, prevention of nutritional deficits in early life may have longterm benefits for individuals and societies. The findings of food neuropsychology and nutritional research on child mental development should inform public health nutrition practice and policymaking related to promoting healthy brain development.

\section{References}

Adamo, A.M., and Oteiza, P.I. (2010). Zinc deficiency and neurodevelopment: the case of neurons. BioFactors 36(2): 117-124.

Armony-Sivan, R., Eidelman, A.I., Lanir, A., Sredni, D., and Yehuda, S. (2004). Iron status and neurobehavioral development of premature infants. J. Perinatol. 24(12): 757-762.

Basatemur, E., Gardiner, J., Williams, C., Melhuish, E., Barnes, J., and Sutcliffe, A. (2013). Maternal prepregnancy BMI and child cognition: a longitudinal cohort study. Pediatrics 131(1): 56-63.

Bath, S.C., Steer, C.D., Golding, J., Emmett, P., and Rayman, M.P. (2013). Effect of inadequate iodine status in UK pregnant women on cognitive outcomes in their children: results from the Avon Longitudinal Study of Parents and Children (ALSPAC). Lancet 382(9889): 331-337.

Beard, J.L., and Connor, J.R. (2003). Iron status and neural functioning. Annu. Rev. Nutr. 23: 41-58. 
Black, M.M., Sazawal, S., Black, R.E., Khosla, S., Kumar, J., and Menon, V. (2004). Cognitive and motor development among small-for-gestational-age infants: impact of zinc supplementation, birth weight, and caregiving practices. Pediatrics 113(5): 1297-1305.

Black, M.M., Walker, S.P., Fernald, L.C.H., Andersen, C.T., DiGirolamo, A.M., Lu, C., McCoy, D.C., Fink, G., Shawar, Y.R., Shiffman, J., Devercelli, A.E., Wodon, Q.T., Vargas-Barón, E., and Grantham-McGregor, S. (2017). Early childhood development coming of age: science through the life course. Lancet 389(10064): 77-90.

Bornstein, M.H. (1989). Sensitive periods in development: structural characteristics and causal interpretations. Psychol. Bull. 105(2): 179-197.

Bourre, J.M., Francois, M., Youyou, A., Dumont, O., Piciotti, M., Pascal, G., and Durand, G. (1989). The effects of dietary alpha-linolenic acid on the composition of nerve membranes, enzymatic activity, amplitude of electrophysiological parameters, resistance to poisons and performance of learning tasks in rats. J. Nutr. 119(12): 1880-1892.

Brown, A.S., Susser, E.S., Lin, S.P., Neugebauer, R., and Gorman, J.M. (1995). Increased risk of affective disorders in males after second trimester prenatal exposure to the Dutch hunger winter of 1944-45. Br. J. Psychiatry 166(5): 601-606.

Carlson, E.S., Tkac, I., Magid, R., O'Connor, M.B., Andrews, N.C., Schallert, T., Gunshin, H., Georgieff, M.K., and Petryk, A. (2009). Iron is essential for neuron development and memory function in mouse hippocampus. J. Nutr. 139(4): 672-679.

Christian, P., Murray-Kolb, L.E., Khatry, S.K., Katz, J., Schaefer, B.A., Cole, P.M., Leclerq, S.C., and Tielsch, J.M. (2010). Prenatal micronutrient supplementation and intellectual and motor function in early schoolaged children in Nepal. JAMA 304(24): 2716-2723.

Clandinin, M.T., Chappell, J.E., Leong, S., Heim, T., Swyer, P.R., and Chance, G.W. (1980a). Extrauterine fatty acid accretion in infant brain: implications for fatty acid requirements. Early Hum. Dev. 4(2): 131-138.

Clandinin, M.T., Chappell, J.E., Leong, S., Heim, T., Swyer, P.R., and Chance, G.W. (1980b). Intrauterine fatty acid accretion rates in human brain: implications for fatty acid requirements. Early Hum. Dev. 4(2): 121129.

Colombo, J. (1982). The critical period concept: research, methodology, and theoretical issues. Psychol. Bull. 91(2): 260-275.

Colombo, J., Carlson, S.E., Cheatham, C.L., Shaddy, D.J., Kerling, E.H., Thodosoff, J.M., Gustafson, K.M., and Brez, C. (2013). Long-term effects of LCPUFA supplementation on childhood cognitive outcomes. Am. J. Clin. Nutr. 98(2): 403-412.

Colombo, J., Kannass, K.N., Shaddy, D.J., Kundurthi, S., Maikranz, J.M., Anderson, C.J., Blaga, O.M., and Carlson, S.E. (2004). Maternal DHA and the development of attention in infancy and toddlerhood. Child Dev. 75(4): 1254-1267.

Colombo, J., Zavaleta, N., Kannass, K.N., Lazarte, F., Albornoz, C., Kapa, L.L., and Caulfield, L.E. (2014). Zinc supplementation sustained normative neurodevelopment in a randomized, controlled trial of Peruvian infants aged 6-18 months. J. Nutr. 144(8): 1298-1305.

Contu, L., and Hawkes, C.A. (2017). A review of the impact of maternal obesity on the cognitive function and mental health of the offspring. Int. J. Mol. Sci. 18(5): 1093.

Cusick, S.E., and Georgieff, M.K. (2012). Nutrient supplementation and neurodevelopment: timing is the key. Arch. Pediatr. Adolesc. Med. 166(5): 481-482.

Delgado-Noguera, M.F., Calvache, J.A., and Bonfill Cosp, X. (2010). Supplementation with long chain polyunsaturated fatty acids (LCPUFA) to breastfeeding mothers for improving child growth and development. Cochrane Database Syst. Rev. 12: CD007901.

Dinan, T.G., and Cryan, J.F. (2012). Regulation of the stress response by the gut microbiota: implications for psychoneuroendocrinology. Psychoneuroendocrinology 37(9): 1369-1378.

Dinan, T.G., Stilling, R.M., Stanton, C., and Cryan, J.F. (2015). Collective unconscious: how gut microbes shape human behavior. J. Psychiatr. Res. 63: 1-9.

Dölp, A., Schneider-Momm, K., Heiser, P., Clement, C., Rauh, R., Clement, H.-W., Schulz, E., and Fleischhaker, C. (2020). Oligoantigenic diet improves children's ADHD rating scale scores reliably in added videorating. Front. Psychiatry 11: 730.

Dong, J., Yin, H., Liu, W., Wang, P., Jiang, Y., and Chen, J. (2005). Congenital iodine deficiency and hypothyroidism impair LTP and decrease C-fos and C-jun expression in rat hippocampus. Neurotoxicology 26(3) 417-426.

Duncan, J.R., and Hurley, L.S. (1978). Thymidine kinase and DNA polymerase activity in normal and zinc deficient developing rat embryos. Proc. Soc. Exp. Biol. Med. 159(1): 39-43.

Felt, B.T., and Lozoff, B. (1996). Brain iron and behavior of rats are not normalized by treatment of iron deficiency anemia during early development. J. Nutr. 126(3): 693-701.

Fernandez-Real, J.-M., Serino, M., Blasco, G., Puig, J., Daunis-i-Estadella, J., Ricart, W., Burcelin, R., Fernández-Aranda, F., and Portero-Otin, M. (2015). Gut microbiota interacts with brain microstructure and function. J. Clin. Endocrinol. Metab. 100(12): 4505-4513.

Flannery, J.E., Stagaman, K., Burns, A.R., Hickey, R.J., Roos, L.E., Giuliano, R.J., Fisher, P.A., and Sharpton, T.J. (2020). Gut feelings begin in childhood: the gut metagenome correlates with early environment, caregiving, and behavior. mBio 11(1): e02780-19.

Gardner, J.M.M., Powell, C.A., Baker-Henningham, H., Walker, S.P., Cole, T.J., and Grantham-McGregor, S.M. (2005). Zinc supplementation and psychosocial stimulation: effects on the development of undernourished Jamaican children. Am. J. Clin. Nutr. 82(2): 399-405.

Georgieff, M.K. (2007). Nutrition and the developing brain: nutrient priorities and measurement. Am. J. Clin. Nutr. 85(2): 614S-620S.

Georgieff, M.K., and Rao, R. (2001). The role of nutrition in cognitive development. In: Nelson, C.A., and Luciana, M. (Ed.). Handbook of developmental cognitive neuroscience. MIT Press, pp. 491-504.

Getz, K.D., Anderka, M.T., Werler, M.M., and Jick, S.S. (2016). Maternal prepregnancy body mass index and autism spectrum disorder among offspring: a population-based case-control study. Paediatr. Perinat. Epidemiol. 30(5): 479-487.

Golub, M.S., Keen, C.L., Gershwin, M.E., and Hendrickx, A.G. (1995). Developmental zinc deficiency and behavior. J. Nutr. 125(8 Suppl): 2263S2271 S.

Gotlieb, S.J., Biasini, F.J., and Bray, N.W. (1988). Visual recognition memory in IUGR and normal birth-weight infants. Infant Behav. Dev. 11(2): 223-228.

Greminger, A.R., Lee, D.L., Shrager, P., and Mayer-Pröschel, M. (2014). Gestational iron deficiency differentially alters the structure and function of white and gray matter brain regions of developing rats. J. Nutr. 144(7): 1058-1066.

Haber, S.N., and Rauch, S.L. (2010). Neurocircuitry: a window into the networks underlying neuropsychiatric disease. Neuropsychopharmacology 35(1): 1-3.

Helland, I.B., Smith, L., Saarem, K., Saugstad, O.D., and Drevon, C.A. (2003). Maternal supplementation with very-long-chain $n-3$ fatty acids during pregnancy and lactation augments children's IQ at 4 years of age. Pediatrics 111(1): e39-44.

Hibbard, E., and Smithells, R.W. (1965). Folic acid metabolism and human embryopathy. Lancet 285(7398): 1254

Howard, A.L., Robinson, M., Smith, G.J., Ambrosini, G.L., Piek, J.P., and Oddy, W.H. (2011). ADHD is associated with a "Western" dietary pattern in adolescents. J. Atten. Disord. 15(5): 403-411.

Hu, F.B. (2002). Dietary pattern analysis: a new direction in nutritional epidemiology. Curr. Opin. Lipidol. 13(1): 3-9.

Innis, S.M. (2008). Dietary omega 3 fatty acids and the developing brain. Brain Res. 1237: 35-43.

Insel, T.R., and Cuthbert, B.N. (2009). Endophenotypes: bridging genomic complexity and disorder heterogeneity. Biol. Psychiatry 66(11): 988989.

Jacka, F.N., O’Neil, A., Itsiopoulos, C., Opie, R., Cotton, S., Mohebbi, M., Castle, D., Dash, S., Mihalopoulos, C., Chatterton, M.L., Brazionis, L. Dean, O.M., Hodge, A., and Berk, M. (2018). The SMILES trial: an important first step. BMC Med. 16(1): 237.

Jacka, F.N., O'Neil, A., Opie, R., Itsiopoulos, C., Cotton, S., Mohebbi, M., Castle, D., Dash, S., Mihalopoulos, C., Chatterton, M.L., Brazionis, L., Dean, O.M., Hodge, A.M., and Berk, M. (2017). A randomised controlled trial of dietary improvement for adults with major depression (the 'SMILES' trial). BMC Med. 15(1): 23

Jacka, F.N., Ystrom, E., Brantsaeter, A.L., Karevold, E., Roth, C., Haugen, M., Meltzer, H.M., Schjolberg, S., and Berk, M. (2013). Maternal and early postnatal nutrition and mental health of offspring by age 5 years: a prospective cohort study. J. Am. Acad. Child Adolesc. Psychiatry 
52(10): 1038-1047.

Jo, H., Schieve, L.A., Sharma, A.J., Hinkle, S.N., Li, R., and Lind, J.N. (2015). Maternal prepregnancy body mass index and child psychosocial development at 6 years of age. Pediatrics 135(5): e1198-1209.

John, C.C., Black, M.M., and Nelson, C.A. (2017). Neurodevelopment: the impact of nutrition and inflammation during early to middle childhood in low-resource settings. Pediatrics (Suppl 1): S59-S71.

Jones, D.G., and Dyson, S.E. (1981). The influence of protein restriction, rehabilitation and changing nutritional status on synaptic development: a quantitative study in rat brain. Brain Res. 208(1): 97-111.

Kretchmer, N., Beard, J.L., and Carlson, S. (1996). The role of nutrition in the development of normal cognition. Am. J. Clin. Nutr. 63(6): 997S10015

Kris-Etherton, P.M., Grieger, J.A., and Etherton, T.D. (2009). Dietary reference intakes for DHA and EPA. Prostaglandins Leukot. Essent. Fatty Acids 81(2-3): 99-104.

Lake, A., and Chan, M. (2015). Putting science into practice for early child development. Lancet 385(9980): 1816-1817.

Lange, K.W. (2017). Dietary factors in the etiology and therapy of attention deficit/hyperactivity disorder. Curr. Opin. Clin. Nutr. Metab. Care 20(6): 464-469.

Lange, K.W. (2018a). Diet, exercise, and mental disorders - public health challenges of the future. Mov. Nutr. Health Dis. 2: 39-59.

Lange, K.W. (2018b). Do food bioactives play a role in attention-deficit/ hyperactivity disorder? J. Food Bioact. 4: 1-7.

Lange, K.W. (2020a). Lipids in the treatment of neurodegenerative diseases. In: Shahidi, F. (Ed.). Bailey's Industrial Oil and Fat Products. Wiley, pp. 1-17.

Lange, K.W. (2020b). Micronutrients and diets in the treatment of attention-deficit/hyperactivity disorder: chances and pitfalls. Front. Psychiatry 11: 102.

Lange, K.W. (2020c). Omega-3 fatty acids and mental health. Glob. Health J. $4(1): 18-30$

Lange, K.W., Hauser, J., Lange, K.M., Makulska-Gertruda, E., Nakamura, Y., Reissmann, A., Sakaue, Y., Takano, T., and Takeuchi, Y. (2017). The role of nutritional supplements in the treatment of ADHD: what the evidence says. Curr. Psychiatry Rep. 19(2): 8.

Lange, K.W., Hauser, J., and Reissmann, A. (2015). Gluten-free and caseinfree diets in the therapy of autism. Curr. Opin. Clin. Nutr. Metab. Care 18(6): 572-575.

Lange, K.W., Lange, K.M., Nakamura, Y., and Kanaya, S. (2020). Is there a role of gut microbiota in mental health? J. Food Bioact. 9: 4-9.

Lange, K.W., Nakamura, Y., Gosslau, A.M., and Li, S. (2019). Are there serious adverse effects of omega-3 polyunsaturated fatty acid supplements? J. Food Bioact. 7: 1-6.

Laurent, J.S., Watts, R., Adise, S., Allgaier, N., Chaarani, B., Garavan, H., Potter, A., and Mackey, S. (2020). Associations among body mass index, cortical thickness, and executive function in children. JAMA Pediatr. 174(2): 170-177.

Liu, J., He, P., Li, L., Shen, T., Wu, M., Hu, J., Zhuang, Y., Yin, J., and He, G. (2014). Study on the association between diet, nutrient and attention deficit hyperactivity disorder among children in Shanghai, Kunshan, Wuxi three kindergarten. Wei Sheng Yan Jiu 43(2): 235-239.

Low, J.A., and Galbraith, R.S. (1974). Pregnancy characteristics of intrauterine growth retardation. Obstet. Gynecol. 44(1): 122-126.

Lozoff, B., Beard, J., Connor, J., Barbara, F., Georgieff, M., and Schallert, T. (2006). Long-lasting neural and behavioral effects of iron deficiency in infancy. Nutr. Rev. 64(5 Pt 2): S34-S43; discussion S72-S91.

Lozoff, B., Castillo, M., Clark, K.M., and Smith, J.B. (2012). Iron-fortified vs low-iron infant formula: developmental outcome at 10 years. Arch. Pediatr. Adolesc. Med. 166(3): 208-215.

Luby, J.L. (2015). Poverty's most insidious damage: the developing brain JAMA Pediatr. 169(9): 810-811.

Luxwolda, M.F., Kuipers, R.S., Boersma, E.R., van Goor, S.A., Dijck-Brouwer, D.A.J., Bos, A.F., and Muskiet, F.A.J. (2014). DHA status is positively related to motor development in breastfed African and Dutch infants. Nutr. Neurosci. 17(3): 97-103.

McEchron, M.D., Cheng, A.Y., Liu, H., Connor, J.R., and Gilmartin, M.R. (2005). Perinatal nutritional iron deficiency permanently impairs hippocampus-dependent trace fear conditioning in rats. Nutr. Neurosci. 8(3): 195-206.
Merialdi, M., Caulfield, L.E., Zavaleta, N., Figueroa, A., Dominici, F., and Dipietro, J.A. (2004). Randomized controlled trial of prenatal zinc supplementation and the development of fetal heart rate. Am. J. Obstet. Gynecol. 190(4): 1106-1112.

Moriguchi, T., Greiner, R.S., and Salem, N. (2000). Behavioral deficits associated with dietary induction of decreased brain docosahexaenoic acid concentration. J. Neurochem. 75(6): 2563-2573.

Murray-Kolb, L.E., Khatry, S.K., Katz, J., Schaefer, B.A., Cole, P.M., Leclerq, S.C., Morgan, M.E., Tielsch, J.M., and Christian, P. (2012). Preschool micronutrient supplementation effects on intellectual and moto function in school-aged Nepalese children. Arch. Pediatr. Adolesc. Med. 166(5): 404-410.

Navarro, D., Alvarado, M., Navarrete, F., Giner, M., Obregon, M.J., Manzanares, J., and Berbel, P. (2015). Gestational and early postnatal hypothyroidism alters VGluT1 and VGAT bouton distribution in the neocortex and hippocampus, and behavior in rats. Front. Neuroanat. 9: 9.

Neuringer, M., Connor, W.E., Lin, D.S., Barstad, L., and Luck, S. (1986). Biochemical and functional effects of prenatal and postnatal omega 3 fatty acid deficiency on retina and brain in rhesus monkeys. Proc. Natl. Acad. Sci. U S A 83(11): 4021-4025.

Nigg, J.T., Lewis, K., Edinger, T., and Falk, M. (2012). Meta-analysis of attention-deficit/hyperactivity disorder or attention-deficit/hyperactivity disorder symptoms, restriction diet, and synthetic food color additives. J. Am. Acad. Child Adolesc. Psychiatry 51(1): 86-97.e8.

Norr, M.E., Hect, J.L., Lenniger, C.J., van den Heuvel, M., and Thomason, M.E. (2020). An examination of maternal prenatal BMI and human fetal brain development. J. Child Psychol. Psychiatry. 62(4): 458-469.

O'Connor, D.L., Hall, R., Adamkin, D., Auestad, N., Castillo, M., Connor, W.E., Connor, S.L., Fitzgerald, K., Groh-Wargo, S., Hartmann, E.E., Jacobs, J., Janowsky, J., Lucas, A., Margeson, D., Mena, P., Neuringer, M., Nesin, M., Singer, L., Stephenson, T., Szabo, J., and Zemon, V. (2001). Growth and development in preterm infants fed long-chain polyunsaturated fatty acids: a prospective, randomized controlled trial. Pediatrics 108(2): 359-371.

O’Neil, A., Quirk, S.E., Housden, S., Brennan, S.L., Williams, L.J., Pasco, J.A., Berk, M., and Jacka, F.N. (2014). Relationship between diet and mental health in children and adolescents: a systematic review. Am. J. Public Health 104(10): e31-42.

Osendarp, S.J.M., Baghurst, K.I., Bryan, J., Calvaresi, E., Hughes, D., Hussaini, M., Karyadi, S.J.M., van Klinken, B.J.-W., van der Knaap, H.C.M., Lukito, W., Mikarsa, W., Transler, C., and Wilson, C. (2007). Effect of a 12-mo micronutrient intervention on learning and memory in wellnourished and marginally nourished school-aged children: 2 parallel, randomized, placebo-controlled studies in Australia and Indonesia. Am. J. Clin. Nutr. 86(4): 1082-1093.

$\varnothing$ yen, J., Kvestad, I., Midtb $\varnothing$, L.K., Graff, I.E., Hysing, M., Stormark, K.M., Markhus, M.W., Baste, V., Frøyland, L., Koletzko, B., Demmelmair, H., Dahl, L., Lie, $\varnothing$., and Kjellevold, M. (2018). Fatty fish intake and cognitive function: FINS-KIDS, a randomized controlled trial in preschool children. BMC Med. 16(1): 41.

Parletta, N., Zarnowiecki, D., Cho, J., Wilson, A., Bogomolova, S., Villani, A., Itsiopoulos, C., Niyonsenga, T., Blunden, S., Meyer, B., Segal, L., Baune, B.T., and O'Dea, K. (2019). A Mediterranean-style dietary intervention supplemented with fish oil improves diet quality and mental health in people with depression: A randomized controlled trial (HELFIMED). Nutr. Neurosci. 22(7): 474-487.

Pelsser, L.M., Frankena, K., Toorman, J., and Rodrigues Pereira, R. (2017). Diet and $A D H D$, reviewing the evidence: a systematic review of metaanalyses of double-blind placebo-controlled trials evaluating the efficacy of diet interventions on the behavior of children with ADHD. PLoS One 12(1): e0169277.

Pina-Camacho, L., Jensen, S.K., Gaysina, D., and Barker, E.D. (2015). Maternal depression symptoms, unhealthy diet and child emotionalbehavioural dysregulation. Psychol. Med. 45(9): 1851-1860.

Pollitt, E., Gorman, K.S., Engle, P.L., Rivera, J.A., and Martorell, R. (1995). Nutrition in early life and the fulfillment of intellectual potential. J. Nutr. 125(4 Suppl): 1111S-1118S.

Portwood, M.M. (2006). The role of dietary fatty acids in children's behaviour and learning. Nutr. Health 18(3): 233-247.

Prado, E.L., and Dewey, K.G. (2014). Nutrition and brain development in 
early life. Nutr. Rev. 72(4): 267-284.

Reissmann, A., Hauser, J., Stollberg, E., and Lange, K.W. (2020). Gluten-free and casein-free diets in the management of autism spectrum disorder: A systematic literature review. Mov. Nutr. Health Dis. 4: 21-38.

Richardson, A.J., and Montgomery, P. (2005). The Oxford-Durham study: a randomized, controlled trial of dietary supplementation with fatty acids in children with developmental coordination disorder. Pediatrics 115(5): 1360-1366.

Ríos-Hernández, A., Alda, J.A., Farran-Codina, A., Ferreira-García, E., and Izquierdo-Pulido, M. (2017). The Mediterranean diet and ADHD in children and adolescents. Pediatrics 139(2): e20162027.

Robinson, M., Zubrick, S.R., Pennell, C.E., van Lieshout, R.J., Jacoby, P., Beilin, L.J., Mori, T.A., Stanley, F.J., Newnham, J.P., and Oddy, W.H. (2013). Pre-pregnancy maternal overweight and obesity increase the risk for affective disorders in offspring. J. Dev. Orig. Health Dis. 4(1): 42-48.

Rodriguez, A. (2010). Maternal pre-pregnancy obesity and risk for inattention and negative emotionality in children. J. Child Psychol. Psychiatry 51(2): 134-143.

Sanchez, C.E., Barry, C., Sabhlok, A., Russell, K., Majors, A., Kollins, S.H., and Fuemmeler, B.F. (2018). Maternal pre-pregnancy obesity and child neurodevelopmental outcomes: a meta-analysis. Obes. Rev. 19(4): 464-484.

Sánchez-Villegas, A., Cabrera-Suárez, B., Molero, P., González-Pinto, A., Chiclana-Actis, C., Cabrera, C., Lahortiga-Ramos, F., FloridoRodríguez, M., Vega-Pérez, P., Vega-Pérez, R., Pla, J., Calviño-Cabada, M.J., Ortuño, F., Navarro, S., Almeida, Y., and Hernández-Fleta, J.L. (2019). Preventing the recurrence of depression with a Mediterranean diet supplemented with extra-virgin olive oil. The PREDI-DEP trial: study protocol. BMC Psychiatry 19(1): 63.

Sandstead, H.H. (1985). W.O. Atwater memorial lecture. . Nutr. Rev. 43(5): 129-137.

SanGiovanni, J.P., Parra-Cabrera, S., Colditz, G.A., Berkey, C.S., and Dwyer, J.T. (2000). Meta-analysis of dietary essential fatty acids and longchain polyunsaturated fatty acids as they relate to visual resolution acuity in healthy preterm infants. Pediatrics 105(6): 1292-1298.

Sarkar, A., Harty, S., Lehto, S.M., Moeller, A.H., Dinan, T.G., Dunbar, R.I.M., Cryan, J.F., and Burnet, P.W.J. (2018). The microbiome in psychology and cognitive neuroscience. Trends Cogn. Sci. 22(7): 611-636.

Shonkoff, J.P., and Garner, A.S. (2012). The lifelong effects of early childhood adversity and toxic stress. Pediatrics 129(1): e232-46.

Siddappa, A.M., Georgieff, M.K., Wewerka, S., Worwa, C., Nelson, C.A., and Deregnier, R.-A. (2004). Iron deficiency alters auditory recognition memory in newborn infants of diabetic mothers. Pediatr. Res. 55(6): 1034-1041.

Simmer, K. (2001). Long-chain polyunsaturated fatty acid supplementation in infants born at term. Cochrane Database Syst. Rev.(4): CD000376.
Skeaff, S.A. (2011). lodine deficiency in pregnancy: the effect on neurodevelopment in the child. Nutrients 3(2): 265-273.

Small, L., and Aplasca, A. (2016). Child Obesity and Mental Health: A Complex Interaction. Child Adolesc. Psychiatr. Clin. N. Am. 25(2): 269-282.

Spinillo, A., Stronati, M., Ometto, A., Fazzi, E., Lanzi, G., and Guaschino, S. (1993). Infant neurodevelopmental outcome in pregnancies complicated by gestational hypertension and intra-uterine growth retardation. J. Perinat. Med. 21(3): 195-203.

Steenweg-de Graaff, J., Tiemeier, H., Steegers-Theunissen, R.P.M., Hofman, A., Jaddoe, V.W.V., Verhulst, F.C., and Roza, S.J. (2014). Maternal dietary patterns during pregnancy and child internalising and externalising problems. The Generation R Study. Clinical nutrition 33(1): 115-121.

Strauss, R.S., and Dietz, W.H. (1998). Growth and development of term children born with low birth weight: effects of genetic and environmental factors. J. Pediatr. 133(1): 67-72.

Susser, E.S., and Lin, S.P. (1992). Schizophrenia after prenatal exposure to the Dutch Hunger Winter of 1944-1945. Arch. Gen. Psychiatry 49(12): 983-988.

Tamura, T., Goldenberg, R.L., Hou, J., Johnston, K.E., Cliver, S.P., Ramey, S.L., and Nelson, K.G. (2002). Cord serum ferritin concentrations and mental and psychomotor development of children at five years of age. J. Pediatr. 140(2): 165-170.

Tseng, K.Y., Chambers, R.A., and Lipska, B.K. (2009). The neonatal ventral hippocampal lesion as a heuristic neurodevelopmental model of schizophrenia. Behav. Brain Res. 204(2): 295-305.

Vollet, K., Ghassabian, A., Sundaram, R., Chahal, N., and Yeung, E.H. (2017). Prenatal fish oil supplementation and early childhood development in the Upstate KIDS Study. J. Dev. Orig. Health Dis. 8(4): 465-473.

Walker, S.P., Wachs, T.D., Gardner, J.M., Lozoff, B., Wasserman, G.A., Pollitt, E., and Carter, J.A. (2007). Child development: risk factors for adverse outcomes in developing countries. Lancet 369(9556): 145-157.

Weaver, I.C.G. (2014). Integrating early life experience, gene expression, brain development, and emergent phenotypes: unraveling the thread of nature via nurture. Adv. Genet. 86: 277-307.

White, N.M., and McDonald, R.J. (2002). Multiple parallel memory systems in the brain of the rat. Neurobiol. Learn. Mem. 77(2): 125-184.

Wiggins, R.C., Fuller, G., and Enna, S.J. (1984). Undernutrition and the development of brain neurotransmitter systems. Life Sci. 35(21): 2085-2094.

Williams, G.R. (2008). Neurodevelopmental and neurophysiological actions of thyroid hormone. J. Neuroendocrinol. 20(6): 784-794.

Winick, M. (1985). Prenatal protein-calorie malnutrition and brain development. Prog. Clin. Biol. Res. 163B: 397-402.

Zhou, F., Wu, F., Zou, S., Chen, Y., Feng, C., and Fan, G. (2016). Dietary, Nutrient Patterns and Blood Essential Elements in Chinese Children with ADHD. Nutrients 8(6): E352. 